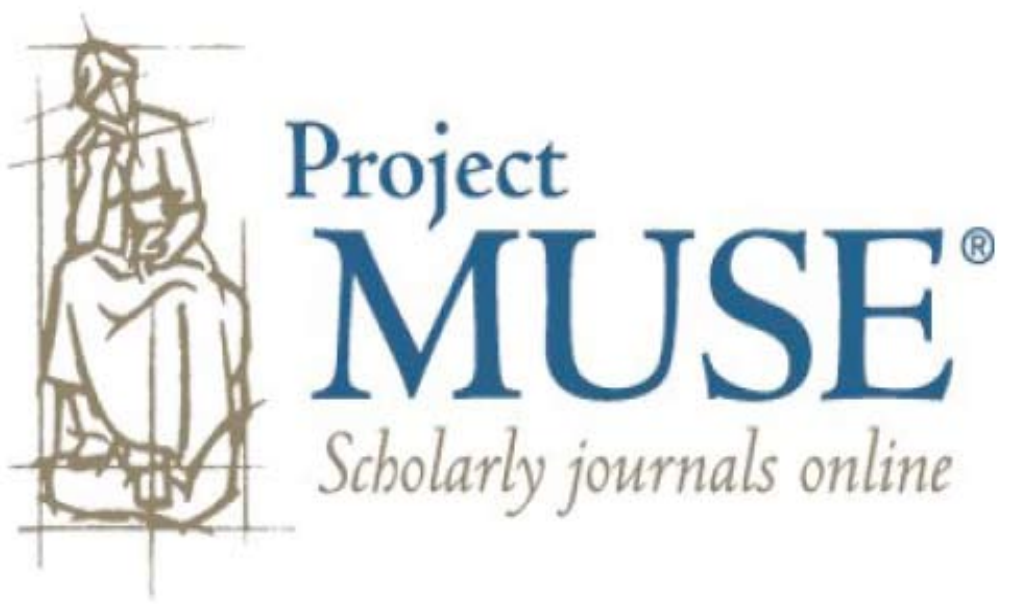




\title{
Predictors of Influenza Vaccination in an Urban Community during a National Shortage
}

\author{
Erica Phillips-Caesar, MD, MS \\ Micaela H. Coady, MS \\ Shannon Blaney, MPH \\ Danielle C. Ompad, PhD \\ Sarah Sisco, MPH, MSSW \\ Kathryn Glidden, RN \\ David Vlahov, PhD \\ Sandro Galea, MD, MPH, DrPH \\ for the Project VIVA Intervention Working Group
}

\begin{abstract}
Little is known about the impact of vaccine shortages on vaccination rates among disadvantaged populations in the United States. We compared factors associated with influenza vaccination rates during a vaccine shortage (2004-2005) and a non-shortage (2003-2004) year among adults in predominantly minority New York City neighborhoods. Thirty-one percent of participants received influenza vaccine during the non-shortage year compared with $18 \%$ during the shortage. While fewer people received the influenza vaccine during the shortage, a higher proportion of the vaccinated were in a high-risk group $(68 \%$ vs. $52 \%$, respectively). People were less likely to have been vaccinated during the shortage if they were Black. This study suggests that vaccination rates were lower during the shortage period among Blacks and those who are not explicitly a focus of national vaccination outreach campaigns. Such groups are less likely to be vaccinated when vaccines are scarce.
\end{abstract}

Key words: Influenza, vaccination, hard-to-reach populations, urban, disadvantaged.

$\mathrm{O}$ n October 5, 2004, Chiron Corporation notified the Centers for Disease Control and Prevention (CDC) that none of its inactivated influenza vaccine would be available for distribution in the United States for the 2004-2005 influenza season. At that time, the $\mathrm{CDC}$, in coordination with the Advisory Committee on Immunization Practices (ACIP), issued interim recommendations to direct available inactivated influenza vaccine to high-risk individuals. ${ }^{1}$ This was the second time in recent years that a delay in the distribution of influenza vaccine would result in a call for voluntary

ERICA PHILLIPS-CAESAR is an Assistant Professor in the Department of Medicine, Weill Medical College of Cornell University, where she can be reached at 505 East 70th Street, HT-4, New York, NY 10021; (718) 482-0053; erp2001@med.cornell.edu. MICAELA COADY, SHANNON BLANEY, DANIELLE OMPAD, SARAH SISCO, KATHRYN GLIDDEN, DAVID VLAHOV, and SANDRO GALEA are all affiliated with the Center for Urban Epidemiologic Studies, New York Academy of Medicine. Dr. Galea is also affiliated with the University of Michigan School of Public Health in Ann Arbor. 
rationing of the vaccine, ${ }^{2}$ a tactic that did not succeed during the influenza season of 2000-2001. During that season, employers and others serving low-risk populations received vaccine while physicians serving primarily older and high-risk populations frequently did not. ${ }^{3}$ Therefore, during the 2004-2005 influenza season, we examined vaccination rates among residents of socioeconomically disadvantaged areas of New York City. We examined the factors associated with receipt of vaccine during the shortage among residents of these two communities in order to inform future efforts to direct scarce vaccine resources to members of high-risk populations.

\section{Methods}

The data presented in this study are a subset of the data collected from Project VIVA (Venue-Intensive Vaccines for Adults), a multi-level community-based participatory research (CBPR) intervention designed to immunize hard-to-reach (HTR) populations in low-income neighborhoods in East Harlem and the Bronx. There is no accepted definition of HTR populations; populations of interest for this project included substance abusers, sex workers, undocumented immigrants, people who are homeless, and homebound elderly.

The parent project was structured in 5 phases: The first phase (February-October 2004) was an enumeration and survey of the target population, a detailed description of which has been previously published. ${ }^{4}$ Phase II, the focus of this paper, was a survey to examine access to vaccination during the national shortage (October-December 2004). Phase III (January-March 2005) was the implementation of a pilot door-to-door influenza vaccination program. Using a cross-over design we randomly selected 4 of the 8 study neighborhoods to receive the pilot vaccination program initially. Then, in phase IV (September-October 2005), the remaining 4 neighborhoods received the vaccine program over a period of 10 days. ${ }^{5}$ The latter vaccination effort was used to test the feasibility of rapid vaccination of HTR populations in the event of an influenza pandemic or bioterrorist threat. The most promising elements of the project were disseminated during the fifth and final phase of the project.

The eight study neighborhoods were identified through consultation with communitybased organizations in the communities of East Harlem and the Bronx. Anestimated 24,000 individuals reside in the neighborhoods (each roughly six to eight blocks in size). ${ }^{*}$ Census data indicate that the neighborhoods are 31\% Black and 65\% Latino;

\footnotetext{
* The neighborhoods in East Harlem are the following: 108th Street to 112th Street, between Lexington and Park Avenues, 109th Street to 111th Street, between Park and Madison (EH1); 119th Street to 125th Street, between 3rd and Lexington Avenues, 121st Street to 123rd Street, between Lexington and Park Avenues (EH2); 116th Street to 117th Street, between 1st and Madison Avenues (EH3). The neighborhoods in the Bronx are the following: 146th Street to 149th Street, between Brook and Willis/Bergen Avenues (BX4); the areas bounded by Simpson Street and Intervale Avenue on the east and west, Westchester Avenue to the north, and Beck/Fox Streets to the south (BX5); from Hunts Point Avenue to Longfellow Avenue, between Seneca and Garrison Avenues (BX6); Wheeler Avenue to Manor Avenue, between Bruckner Boulevard and Watson Avenue (BX7); 182nd Street to 183rd Street, between Jerome and Aqueduct Avenues, Cameron Place to 182nd Street, between Morris and Jerome Avenues $(\boldsymbol{B X} \mathbf{8})$.
} 
$53 \%$ of residents are female. About half of residents have not completed high school, compared with $28 \%$ in New York City as a whole. Approximately $20 \%$ of people in these neighborhoods are unemployed, $68 \%$ have a total household income of $\$ 30,000$ a year or less, and $45 \%$ lived below the poverty level in 1999. The mean per capita income in the East Harlem neighborhoods is approximately $\$ 10,000$; it is $\$ 8,000$ in the Bronx neighborhoods (compared with an average of $\$ 23,000$ for New York City). ${ }^{6}$ These neighborhoods have some of the highest morbidity and mortality rates secondary to asthma, diabetes, heart disease, HIV, and substance abuse in the city. ${ }^{7}$ People were eligible for participation in the study if they were 18 years of age or older, spoke English or Spanish, and could provide informed consent. The Institutional Review Board of The New York Academy of Medicine approved all phases of the study.

A brief in-person questionnaire was developed to assess: 1) sociodemographic characteristics, including age, gender, race, and education; 2) characteristics that may be associated with social marginalization, including substance abuse and commercial sex work; 3) access to health care; 4) vaccination history; 5) general health; and 6) trust in government and social agencies. In October 2004, at the onset of the vaccine shortage, questions were added to the questionnaire to examine: 1 ) perceptions of the shortage; 2 ) vaccine eligibility based on the CDC's designated priority groups; 3 ) impact of the shortage on participants' present and future receipt of vaccinations and other health care services.

Data were collected using a venue-based application of time-space sampling. ${ }^{8,9}$ Time-space sampling seeks to recruit target populations in places and times where these populations can be reasonably expected to gather. Using extensive fieldwork, consultation with our collaborating community-based organizations, and prior outreach experience described elsewhere, ${ }^{10}$ we identified two street-based venue sites in each of the eight study neighborhoods that were routinely frequented by members of HTR populations (drug outreach centers and meeting places for undocumented immigrants to find off-the books employment). After constructing a sampling frame of venues and associated sampling periods (e.g., a bottle repository on 125th street between 1:00 pm and 4:00 pm) pairs of outreach workers systematically interviewed every willing adult that came through the venue. A brief, anonymous questionnaire was administered to all eligible participants who gave verbal consent. Venue-based sampling was conducted at the same venues in all eight of the study neighbourhoods from February through April of 2004, which represents the non-shortage vaccine period (to which we will refer as the non-shortage period) and from October-December 2004 (to which we will refer as the shortage period). In both phases, participants were provided street-side education on influenza prevention and, during the shortage period, weekly updates and information about locations for eligible people to obtain influenza vaccine.

Sociodemographic characteristics of participants interviewed during the two vaccine seasons were compared and contrasted using the chi-square test for categorical

\footnotetext{
* People designated as being priority groups for vaccination were people who 65 years of age and older, and adults who have heart disease, kidney disease, diabetes, HIV/AIDS, asthma, and other chronic conditions. Health care workers with direct patient contact, and caregivers of and household contact with infants under 6 months of age were also priority groups for vaccination.
} 
variables and Student's t test for continuous variables. Logistic regression analysis was used to assess factors associated with recent influenza vaccination. Recent influenza vaccination was defined as having been vaccinated since the fall of the previous year. Two multivariate models were constructed, one with non-shortage period data, and the other with shortage period data. The non-shortage period model was adjusted for age, history of homelessness, history of injection drug use, health insurance coverage, source of routine medical care, prior use of government, community health or social services, HIV status, and medical indication for the vaccine (e.g., people in CDCdesignated priority groups for vaccination). The shortage period model was adjusted for age, gender, racial/ethnic background, source of routine medical care, HIV status, and medical indication for the vaccine. A significance value of $p<.10$ was chosen as a criterion for variable selection. We chose to include variables in the model that had borderline significant associations with the outcome so as to ensure that we adjusted for all potentially important variables, even those that did not meet the more usual $p<.05$ cutoff. From the final model, odds ratios (ORs) and corresponding 95\% confidence intervals (CIs) were derived. All analyses were performed using SAS software, Version 8 of the SAS system for Windows (SAS Corp., Cary, NC).

\section{Results}

A total of 773 participants were interviewed during the non-shortage period and 272 participants were interviewed during the shortage period. Surveys were excluded if any of the following variables were missing: age, gender, race/ethnicity, health insurance status, routine medical care, source of care, injection of illegal drugs, and presence of medical indications/ contraindications to influenza vaccine. One hundred and eightytwo $(24 \%)$ of the surveys were excluded from the analysis of the non-shortage period, and $62(23 \%)$ were excluded from the shortage period analysis. The analyses presented here are limited to surveys without missing variables. The characteristics of 591 study participants from the non-shortage period and 210 participants from the shortage period are reported in Table 1. Participants included in this analysis did not differ significantly from those excluded with respect to age, race/ethnicity, income, illicit drug use, receipt of routine medical care, HIV status, or indications for influenza vaccination. Respondents excluded from analysis in the non-shortage period were more likely than participants in the shortage period to be uninsured $(\mathrm{p}<.06)$. In addition, respondents excluded from analysis in the shortage period were more likely than participants in the non-shortage period to be male $(\mathrm{p}<.03)$.

Participants in the shortage period were significantly younger in age than those in the non-shortage period (mean age 36 years vs. 39 years). There were more women (79\% vs. $56 \%$ ), more Blacks (25\% vs. $17 \%$ ), and higher household incomes (37\% vs. $26 \%$ ) among participants in the shortage period than among those in the non-shortage period. Congruent with the higher reported income, participants in the shortage period had lower reports of previous homelessness ( $26 \%$ vs. $38 \%$ ), hunger ( $12 \%$ vs. $28 \%$ ), and lifetime injection drug use ( $8 \%$ vs. $13 \%)$. Concerning health care, more participants in the shortage period than in the non-shortage period received routine medical care $(83 \%$ vs. $70 \%)$. Of those participants who had health insurance, shortage period participants 


\section{Table 1.}

\section{CHARACTERISTICS OF PARTICIPANTS INTERVIEWED IN THE NON-SHORTAGE AND SHORTAGE PERIODS ${ }^{a}$}

\begin{tabular}{|c|c|c|c|c|c|}
\hline \multirow[b]{2}{*}{ Characteristics } & \multicolumn{2}{|c|}{$\begin{array}{l}\text { Non-shortage } \\
\quad(n=591)\end{array}$} & \multicolumn{2}{|c|}{$\begin{array}{l}\text { Shortage period } \\
\quad(n=210)\end{array}$} & \multirow[b]{2}{*}{ p-value } \\
\hline & n & $\%$ & $\mathbf{n}$ & $\%$ & \\
\hline \multicolumn{6}{|l|}{ Age } \\
\hline $18-39$ & 308 & 52 & 133 & 63 & \multirow[t]{3}{*}{$<.01$} \\
\hline $40-64$ & 238 & 40 & 74 & 35 & \\
\hline$\geq 65$ & 45 & 8 & 3 & 1 & \\
\hline \multicolumn{6}{|l|}{ Gender } \\
\hline Male & 260 & 44 & 45 & 21 & \multirow[t]{2}{*}{$<.01$} \\
\hline Female & 328 & 56 & 165 & 79 & \\
\hline \multicolumn{6}{|l|}{ Race/ethnicity } \\
\hline Hispanic & 449 & 76 & 142 & 68 & \multirow[t]{3}{*}{.02} \\
\hline Black & 98 & 17 & 53 & 25 & \\
\hline Caucasian/other & 44 & 7 & 15 & 7 & \\
\hline \multicolumn{6}{|l|}{ Income } \\
\hline$\$ 9,600 /$ year or less & 415 & 74 & 131 & 63 & \multirow[t]{2}{*}{$<.01$} \\
\hline$\$ 9,601 /$ year or more & 149 & 26 & 76 & 37 & \\
\hline History of homelessness & 225 & 38 & 54 & 26 & $<.01$ \\
\hline Hungry in the past 6 months & 165 & 28 & 26 & 12 & $<.01$ \\
\hline History of injection drug use & 75 & 13 & 17 & 8 & .07 \\
\hline History of illegal drug use & 358 & 61 & 129 & 61 & .83 \\
\hline History of trading sex & 38 & 6 & 12 & 6 & .70 \\
\hline Has health insurance & 421 & 71 & 167 & 80 & .02 \\
\hline \multicolumn{6}{|l|}{ Health insurance } \\
\hline Government sponsored & 288 & 69 & 103 & 62 & \multirow[t]{3}{*}{$<.01$} \\
\hline Employment sponsored/private & 63 & 15 & 46 & 28 & \\
\hline Other & 67 & 16 & 17 & 10 & \\
\hline Receives routine medical care & 416 & 70 & 174 & 83 & $<.01$ \\
\hline \multicolumn{6}{|l|}{ Location of routine medical care } \\
\hline Hospital clinic/health center & 333 & 80 & 127 & 73 & \multirow[t]{3}{*}{.13} \\
\hline Private doctor & 65 & 16 & 39 & 22 & \\
\hline Other ${ }^{\mathrm{b}}$ & 18 & 4 & 8 & 5 & \\
\hline \multicolumn{6}{|l|}{$\begin{array}{l}\text { Received health/social services from } \\
\text { a government or community agency }\end{array}$} \\
\hline high risk group ${ }^{c}$ & 379 & 64 & 133 & 64 & .90 \\
\hline $\begin{array}{l}{ }^{a} \text { Non-shortage period was February-Ap } \\
\text { b'Other self-reported sources of care we } \\
\text { 'People } 65 \text { years of age and older, adult } \\
\text { disease, diabetes, HIV/AIDS, asthma, a }\end{array}$ & $\begin{array}{l}2004 \text { anc } \\
\text { mergenc } \\
\text { years } 0\end{array}$ & $\begin{array}{l}\text { shortag } \\
\text { departn } \\
\text { age anc }\end{array}$ & $\begin{array}{l}\text { iod was } C \\
\text { s and met } \\
\text { ler who h }\end{array}$ & $\begin{array}{l}\text { ctober-De } \\
\text { ladone pro } \\
\text { ve heart d }\end{array}$ & $\begin{array}{l}\text { nber } 2004 . \\
\text { ams. } \\
\text { ase, kidney }\end{array}$ \\
\hline
\end{tabular}


had private health insurance more often (28\% vs. $15 \%)$. Using the CDC's criteria for immunizing high-risk groups, $48 \%(\mathrm{n}=281)$ of participants in the non-shortage period and $40 \%(n=85)$ of participants in the shortage period met eligibility for influenza vaccination. All values were significant at the $p<.10$ level.

A total of 183 (31\% of) people in the non-shortage period reported receiving the influenza vaccine during the non-shortage season, of whom $57 \%(n=105)$ were in a high-risk group. In the shortage period, while $52 \%$ of people tried to obtain the influenza vaccine, only $18 \%(n=38)$ of participants were successful, of whom $68 \%(n=26)$ were in a high-risk group.

Unadjusted and adjusted associations with receipt of influenza vaccination during the non-shortage period are shown in Table 2. Individuals who were vaccinated were more likely to be older, to have been homeless, to have injected or used illegal drugs, to have health insurance, to have accessed routine medical care, to have received health or social services from a government or community agency, and to be a member of a high-risk group. After multivariate adjustment, a positive association remained between receipt of vaccination and older age (OR 1.02; 95\% CI 1.01-1.04), having health insurance (OR 2.36; 95\% CI 1.36-4.12), receiving routine medical care at a hospital based clinic or health center (OR 2.79, 95\% CI 1.61-4.81) or from another source of care (such as a methadone program) (OR 6.01; 95\% CI 2.00-18.07), and having had an HIV test, whether the results were negative (OR 1.97; 95\% CI 1.15-3.35) or positive (OR 13.86; 95\% CI 4.26-44.08).

Unadjusted and adjusted associations with receipt of influenza vaccination during the shortage period of 2004-2005 appear in Table 3. While older age was again a significant correlate in bivariate analysis we found that men (OR 4.16; 95\% CI 1.95-8.87) and those in a high-risk group (OR 4.15; 95\% CI 1.95-8.81) were almost four times more likely to have been vaccinated than their counterparts. Blacks (OR 0.21; 95\%

\section{Table 2.}

FACTORS ASSOCIATED WITH INFLUENZA VACCINATION DURING THE 2003-2004 NON-SHORTAGE SEASON

\begin{tabular}{|c|c|c|c|}
\hline Variable & $\begin{array}{l}\text { Unadjusted odds } \\
\text { ratio }(95 \% \mathrm{CI})\end{array}$ & p-value & $\begin{array}{l}\text { Adjusted odds } \\
\text { ratio }(95 \% \mathrm{CI})\end{array}$ \\
\hline Age & $1.02(1.01-1.03)$ & $<.01$ & $1.02(1.01-1.04)$ \\
\hline \multicolumn{4}{|l|}{ Gender } \\
\hline Female & Reference & & \\
\hline Male & $.91(.64-1.29)$ & .59 & \\
\hline \multicolumn{4}{|l|}{ Race/ethnicity } \\
\hline Caucasian/other & Reference & & \\
\hline Hispanic & $1.54(.74-3.20)$ & .25 & \\
\hline Black & $1.73(.76-3.92)$ & .19 & \\
\hline
\end{tabular}




\section{Table 2 (continued).}

\begin{tabular}{|c|c|c|c|}
\hline Variable & $\begin{array}{l}\text { Unadjusted odds } \\
\text { ratio }(95 \% \mathrm{CI})\end{array}$ & p-value & $\begin{array}{l}\text { Adjusted odds } \\
\text { ratio }(95 \% \mathrm{CI})\end{array}$ \\
\hline \multicolumn{4}{|l|}{ Income } \\
\hline$\$ 9,600 /$ year or less & Reference & & \\
\hline$\$ 9,601 /$ year or more & $1.02(.68-1.54)$ & .91 & \\
\hline \multicolumn{4}{|l|}{ History of homelessness } \\
\hline No & Reference & & \\
\hline Yes & $1.83(1.28-2.61)$ & $<.01$ & $1.20(.78-1.85)$ \\
\hline \multicolumn{4}{|l|}{ Hungry in the past 6 months } \\
\hline No & Reference & & \\
\hline Yes & $.84(.57-1.25)$ & .40 & \\
\hline \multicolumn{4}{|l|}{ History of injection drug use } \\
\hline No & Reference & & \\
\hline Yes & $2.80(1.71-4.58)$ & $<.01$ & $1.72(.93-3.16)$ \\
\hline \multicolumn{4}{|l|}{ History of illegal drug use } \\
\hline No & Reference & & \\
\hline Yes & $1.74(1.22-2.47)$ & $<.01$ & \\
\hline \multicolumn{4}{|l|}{ History of trading sex for money } \\
\hline No & Reference & & \\
\hline Yes & $1.33(.67-2.64)$ & .41 & \\
\hline \multicolumn{4}{|l|}{ Has health insurance } \\
\hline No & Reference & & \\
\hline Yes & $3.48(2.18-5.56)$ & $<.01$ & $2.36(1.36-4.12)$ \\
\hline \multicolumn{4}{|l|}{ Type of health insurance } \\
\hline Government sponsored & Reference & & \\
\hline Employer sponsored/private & $.74(.42-1.32)$ & .31 & \\
\hline Other & $.68(.38-1.19)$ & .18 & \\
\hline \multicolumn{4}{|c|}{ Receives routine medical care \& location of care } \\
\hline No routine care & Reference & & \\
\hline Hospital clinic/health center & $4.18(2.58-6.78)$ & $<.01$ & $2.79(1.61-4.81)$ \\
\hline Private doctor & $2.05(1.01-4.18)$ & .05 & $1.58(.72-3.45)$ \\
\hline Other & $7.86(2.82-21.91)$ & $<.01$ & $6.01(2.00-18.07)$ \\
\hline \multicolumn{4}{|l|}{ HIV status } \\
\hline Never tested & Reference & & \\
\hline Negative & $2.10(1.35-3.27)$ & $<.01$ & $1.97(1.15-3.35)$ \\
\hline Positive & $17.16(5.98-49.29)$ & $<.01$ & $13.86(4.26-45.08)$ \\
\hline \multicolumn{4}{|c|}{ Received health or social services from a government or community agency } \\
\hline No & Reference & & \\
\hline Yes & $1.63(1.11-2.37)$ & .01 & $.91(.58-1.44)$ \\
\hline \multicolumn{4}{|l|}{ High-risk group } \\
\hline No & Reference & & \\
\hline Yes & $1.77(1.25-2.52)$ & $<.01$ & $.98(.65-1.49)$ \\
\hline
\end{tabular}


CI 0.05-0.86) were less likely to have been vaccinated than their counterparts. These same factors remained statistically significant after multivariate adjustment.

\section{Discussion}

We found low rates of vaccination during non-shortage periods, in particular among high-risk groups younger than 65 years of age. During the 2003-2004 influenza season, only $31 \%$ of our participants reported receiving the influenza vaccine, of whom approximately half were members of a high-risk group. These rates are comparable to New York City data from 2002, which showed 31\% of adults 50-64 years of age, and approximately $35 \%$ of people with chronic health conditions, reported receiving the influenza vaccine. ${ }^{11}$ Low vaccination coverage among minorities and people living in and near poverty is a persistent problem. ${ }^{12}$ Immunization rates correlate with a number of factors, including demographic characteristics, attitudes about vaccination, trust in the health care system, health norms, and barriers to access (including income and immunization delivery methods). ${ }^{13-15}$ Issues of trust was evident in one of our earlier papers where $19 \%$ of participants reported that the vaccine shortage was due to the government not wanting to make the vaccine available. ${ }^{16}$ During the non-shortage period we found that participants who had health insurance and received routine medical care were more likely to be vaccinated. Interestingly, non-traditional sources of health care such as methadone programs and/or being tested for HIV were also associated with being vaccinated. These findings support calls to strengthen and expand access to risk reduction programs for marginalized groups. These programs represent an important opportunity for the provision of broader preventive health services.

During the subsequent vaccine season, we observed even lower rates of vaccination. Although $64 \%$ of high-risk people tried to get the vaccine, only $18 \%$ of them were successful in being vaccinated. This low vaccination rate persisted in our study neighborhoods even when vaccine was more readily available in the later part of the influenza season. During phase III, from January-March 2005, we vaccinated 566 people in 4 of the 8 study neighborhoods. Of the 510 people with available data, only 25 (5\%) had been vaccinated in the past year. Furthermore, participants who were Black were less likely to be vaccinated and those with health insurance or access to routine medical care were not more likely to be vaccinated during this period.

Several of our findings are consistent with national influenza immunization data. Data from the Behavioral Risk Factor Surveillance System demonstrated that among adults aged 65 years or older in designated priority groups for vaccination, race/ethnicity significantly affected coverage both during the shortage and thereafter. In November 2004, the odds that Blacks had been vaccinated were $63 \%$ lower than the odds for Whites, while the odds for Hispanics and Whites did not differ statistically. Although there was no racial difference in vaccination rates among vaccine-priority adults aged 18-64 years (29\% for Whites, 22\% for Blacks, and 23\% for Hispanics) the overall vaccination rates were quite low. ${ }^{17}$

Low immunization rates among high-risk, younger people may be due to several factors. First, the primary use of the influenza vaccine has been to reduce morbidity and mortality among adults 65 years old and older and children ages 6 to 23 months. ${ }^{18,19}$ 


\section{Table 3.}

\section{FACTORS ASSOCIATED WITH INFLUENZA VACCINATION} DURING THE 2004-2005 SHORTAGE SEASON

\begin{tabular}{|c|c|c|c|}
\hline Variable & $\begin{array}{l}\text { Unadjusted odds } \\
\text { ratio }(95 \% \mathrm{CI})\end{array}$ & p-value & $\begin{array}{l}\text { Adjusted odds } \\
\text { ratio }(95 \% \mathrm{CI})\end{array}$ \\
\hline Age & $1.05(1.02-1.09)$ & $<.01$ & $1.05(1.02-1.09)$ \\
\hline $\begin{array}{l}\text { Gender } \\
\quad \text { Female } \\
\text { Male }\end{array}$ & $\begin{array}{l}\text { Reference } \\
4.16(1.95-8.87)\end{array}$ & $<.01$ & $3.42(1.38-8.46)$ \\
\hline $\begin{array}{l}\text { Race/ethnicity } \\
\text { Caucasian/other } \\
\text { Hispanic } \\
\text { Black }\end{array}$ & $\begin{array}{l}\text { Reference } \\
.49(.16-1.55) \\
.21(.05-.86)\end{array}$ & $\begin{array}{l}.23 \\
.03\end{array}$ & $\begin{array}{l}.47(.11-1.92) \\
.12(.02-.64)\end{array}$ \\
\hline $\begin{array}{l}\text { Income } \\
\qquad \$ 9,600 / \text { year or less } \\
\$ 9,601 / \text { year or more }\end{array}$ & $\begin{array}{l}\text { Reference } \\
1.16(.56-2.38)\end{array}$ & .70 & \\
\hline $\begin{array}{l}\text { History of homelessness } \\
\text { No } \\
\text { Yes }\end{array}$ & $\begin{array}{l}\text { Reference } \\
1.43(.66-3.08)\end{array}$ & .36 & \\
\hline $\begin{array}{l}\text { Hungry in the past } 6 \text { months } \\
\text { No } \\
\text { Yes }\end{array}$ & $\begin{array}{l}\text { Reference } \\
.83(.27-2.56)\end{array}$ & .74 & \\
\hline $\begin{array}{l}\text { History of injection drug use } \\
\text { No } \\
\text { Yes }\end{array}$ & $\begin{array}{l}\text { Reference } \\
2.02(.67-6.12)\end{array}$ & .21 & \\
\hline $\begin{array}{l}\text { History of illegal drug use } \\
\text { No } \\
\text { Yes }\end{array}$ & $\begin{array}{l}\text { Reference } \\
1.37(.67-2.78)\end{array}$ & .39 & \\
\hline $\begin{array}{l}\text { History of trading sex for money } \\
\text { No } \\
\text { Yes }\end{array}$ & $\begin{array}{l}\text { Reference } \\
.40(.05-3.16)\end{array}$ & .38 & \\
\hline $\begin{array}{l}\text { Has health insurance } \\
\text { No } \\
\text { Yes }\end{array}$ & $\begin{array}{l}\text { Reference } \\
1.46(.57-3.76)\end{array}$ & .43 & \\
\hline $\begin{array}{l}\text { Type of health insurance } \\
\text { Government sponsored } \\
\text { Employer sponsored/private } \\
\text { Other }\end{array}$ & $\begin{array}{l}\text { Reference } \\
.95(.40-2.27) \\
.52(.11-2.46)\end{array}$ & $\begin{array}{l}.91 \\
.41\end{array}$ & \\
\hline
\end{tabular}


Table 3 (continued).

\begin{tabular}{llll}
\hline \hline Variable & $\begin{array}{c}\text { Unadjusted odds } \\
\text { ratio (95\% CI) }\end{array}$ & p-value & $\begin{array}{c}\text { Adjusted odds } \\
\text { ratio (95\% CI) }\end{array}$ \\
\hline $\begin{array}{l}\text { Receives routine medical care \& } \\
\text { location of care }\end{array}$ & & & \\
$\quad$ No routine care & Reference & & \\
$\quad$ Hospital clinic/health center & $3.18(.71-14.30)$ & .13 & $2.70(.55-13.23)$ \\
$\quad$ Private doctor & $7.56(1.56-36.68)$ & .01 & $5.08(.93-27.84)$ \\
$\quad$ Other & $17.00(2.33-124.19)$ & $<.01$ & $8.31(.87-79.12)$ \\
HIV status & & & \\
$\quad$ Never tested & Reference & & \\
$\quad$ Negative & $3.41(.77-15.04)$ & .11 & $3.75(.64-21.92)$ \\
$\quad$ Positive & $8.29(1.26-54.71)$ & .03 & $3.58(.37-34.53)$ \\
Received health or social services & & & \\
from a government or & & & \\
community agency & & & \\
$\quad$ No & & & \\
$\quad$ Yes & Reference & & \\
High-risk group & $1.30(.61-2.75)$ & .50 & \\
$\quad$ No & & & \\
$\quad$ Yes & Reference & & \\
\hline
\end{tabular}

Second, there is still a lack of awareness of the need for vaccination among adults younger than 65 years with high-risk conditions, such as diabetes or asthma. In a 2003 survey, approximately $75 \%$ of unvaccinated people aged 18-64 years with diabetes reported that they were unaware of the need for influenza vaccine. ${ }^{20}$ Third, targeting adults for vaccination by high-risk conditions has proven to be more challenging than targeting adults based on age. ${ }^{21}$ Together, these factors have resulted in a significant percentage of the at risk population between the ages of 18-64 years remaining unvaccinated. Among this group we found a high rate (61\%) of willingness to be vaccinated during the shortage. High-risk younger adults may be very receptive to receiving vaccination when awareness of the benefits of vaccination is high (as it was during the shortage).

Interestingly this willingness did not translate into similar vaccination rates during the shortage period. Although more participants in the shortage period had access to health care, only $18 \%$ of participants were successful in being vaccinated. We also found that the location of care differed during the two periods. While in both periods individuals who used other sources of care (i.e., methadone programs) were more likely to be vaccinated, during the shortage those who used a private doctor were more likely to be vaccinated than their counterparts who used a hospital-based clinic or health center. This may in part be explained by the lack of a national mechanism to distribute the flu vaccine equally among high-risk individuals when supply is limited. ${ }^{22}$ Influenza 
vaccine is distributed largely through multiple channels in the private sector that have evolved to meet the specific needs of different types of purchasers. A relatively small amount of vaccine is purchased and distributed by the CDC or by state and local health departments. ${ }^{23}$ As a result, during the last vaccine shortage seasons (2001 and 2004) some providers received limited or no supplies of vaccine while other providers received full allotments. In some cases, community- or work-site-based clinics and large store chains received vaccine before physician offices, hospitals, and nursing homes. ${ }^{24}$ These findings suggest an urgent need for the development of a national system to ensure equal and appropriate distribution of vaccine to high-risk groups, particularly when vaccines are in short supply.

Our study had several limitations. First, we relied on self-report of interest in vaccination, which may not translate into future seeking out of vaccination. However, mitigating this concern, prior studies have shown that self-report of influenza vaccination is reliable. ${ }^{25-27}$ Second, this intervention took place in eight small underserved neighborhoods in NYC; it is difficult to know the extent to which these findings are generalizable to other populations in other areas. Third, over the course of the survey there was a notable seasonal difference in the number of participants recruited. Respondents may have visited a venue more than once and thus have multiple chances of selection. Fourth, while this work was informed by an active community participatory process that served to inform all aspects of the intervention, future inquiry into the determinants of vaccination during times of shortage may benefit from qualitative research that may deepen our understanding of why people did or did not get vaccinated. Finally, it is difficult to say if people who agreed to be surveyed differed from those who refused. However, our methods have been validated in other studies ${ }^{28}$ and therefore we believe our results stand.

\section{Conclusion}

Recent studies suggest that the most effective way to minimize influenza-related morbidity and mortality is not only to vaccinate high-risk groups but also those at high-risk of transmitting influenza. ${ }^{29-32}$ This is of vital importance during a time of national preparedness efforts against a future influenza pandemic. Prior infectious disease epidemics have demonstrated that populations with low vaccination coverage are a source for continued spread of disease. During the last smallpox epidemic in the U.S. (Boston 1901-1903), it was only after the implementation of a door-to-door vaccine program and forced vaccination of the homeless that public health officials began to see a steady decline of cases and the end of the epidemic. ${ }^{33}$ Thus, gaining access to members of HTR populations may be key to the success of population-wide vaccination efforts. Our study represents an important step in utilizing non-traditional strategies to address this gap in the health care system.

Given the central role played by individual health care providers and communitybased organizations in delivering vaccines both during shortage and during other periods, these providers may be central to any effort that aims to address the barriers to immunization faced by HTR populations. Interventions that maximize the reach and potential of these organizations may hold promise for increasing vaccination rates 
in HTR populations nationwide. This may be particularly important in an era of vaccination shortages and pandemic preparedness where it is necessary to improve our ability efficiently to deliver vaccine to people who are not only at high risk but who may harbor the disease.

\section{Acknowledgments}

This study was conducted as a part of Project VIVA (Venue-Intensive Vaccination for Adults) and is a collaboration between the Harlem Community and Academic Partnership (HCAP) and the Center for Urban Epidemiologic Studies (CUES). The VIVA Intervention Working Group members are: Ann Boyer (Mt. Sinai Medical Center, Women's Information Network and Birdsong); Robert Brackbill (New York City Department of Health and Mental Hygiene); Brian Brown (Harm Reduction Educators); Jose Caraballo (Palladia, Inc.); Micaela Coady (CUES); Sandro Galea (CUES); Katherine Glidden (CUES); Karyn London (Mt. Sinai Medical Center); Gail Love (Women's Information Network); Pat Monahan (East Harlem Community Health Committee, Inc. and Little Sisters of the Assumption Family Health Services); Danielle Ompad (CUES); Erica Phillips (Weill Cornell Medical College, New York Presbyterian Hospital); Sarah Sisco (CUES); Sharon Stancliff (Harm Reduction Coalition); David Vlahov (CUES); and Linda Weiss (Office of Special Populations at the New York Academy of Medicine). This study was supported by a grant from the National Institute on Drug Abuse (DA017004) and the Merck Foundation.

\section{Notes}

1. Centers for Disease Control and Prevention. Updated interim influenza vaccination recommendations-2004-05 influenza season. MMWR Morb Mortal Wkly Rep. 2004 Dec 24;53(50):1183-4.

2. Delayed supply of influenza vaccine and adjunct ACIP influenza vaccine recommendations for the 2000-01 influenza season. Advisory Committee on Immunization Practices. MMWR Morb Mortal Wkly Rep. 2000 Jul 14;49(27):619-22.

3. Fukuda K, O'Mara D, Singelton JA. How the delayed distribution of influenza vaccine created shortages in 2000 and 2001. Pharmacy and Therapeutics. 2002; 27(5):235-42.

4. Bryant WK, Ompad DC, Sisco S, et al. Determinants of influenza vaccination in hardto-reach urban populations. Prev Med. 2006 Jul;43(1):60-70. Epub 2006 May 8.

5. Coady MH, Weiss L, Galea S, et al. Rapid vaccine distribution in nontraditional settings: lessons learned from project VIVA. J Community Health Nurs. 2007 Summer; 24(2):79-85.

6. U.S. Census Bureau, Phillips JE. Census 2000 Summary File (SF-4). Washington, DC: U.S. Census Bureau, 2007 Jan 19. Available at http://factfinder.census.gov.

7. Karpati A, Lu X, Mostashari F, et al. The health of Central Bronx. NYC Community Health Profiles. 2003;1(40):1-12.

8. Muhib FB, Lin LS, Stueve A, et al. A venue-based method for sampling hard-to-reach populations. Public Health Rep. 2001;116 Suppl 1:216-22.

9. MacKellar D, Valleroy L, Karon J, et al. Surveillance of HIV risk and prevention 
behaviors of men who have sex with men-a national application of venue-based, time-space sampling. Public Health Reports. 2007;122 Suppl 1:39-47.

10. Ompad DC, Galea, S, Fuller CM, et al. Club drug use among minority substance users in New York City. J Psychoactive Drugs. 2004 Sep;36(3):397-9.

11. New York City Department of Health and Mental Hygiene, Division of Disease Control, Bureau of Immunization. Immunization to prevent influenza and pneumonia. New York: New York City Department of Health and Mental Hygiene, NYC Vital Signs, 2002.

12. Egede LE, Zheng D. Racial/ethnic differences in influenza vaccination coverage in high-risk adults. Am J Public Health. 2003 Dec;93(12):2074-8.

13. Pearson DC, Thompson RS. Evaluation of Group Health Cooperative of Puget Sound's Senior Influenza Immunization Program. Public Health Rep. 1994 Jul-Aug; 109(4):571-8.

14. Nichol KL, Margolis KL, Wuorenma J, et al. The efficacy and cost effectiveness of vaccination against influenza among elderly persons living in the community. $\mathrm{N}$ Engl J Med. 1994 Sep 22;331(12):778-84.

15. Lewis-Parmar H, McCann R. Achieving national influenza vaccine targets-an investigation of the factors affecting influenza vaccine uptake in older people and people with diabetes. Commun Dis Public Health. 2002 Jun;5(2):119-26.

16. Ompad DC, Galea S, Blaney S, et al. Access to influenza vaccine in East Harlem and the Bronx during a national vaccine shortage. J Community Health. 2007 Jun;32(3):195-202.

17. Link MW, Ahluwalia IB, Euler GL, et al. Racial and ethnic disparities in influenza vaccination coverage among adults during the 2004-2005 season. Am J Epidemiol. 2006 Mar 15;163(6):571-8. Epub 2006 Jan 27.

18. Thompson WW, Shay DK, Weintraub E, et al. Mortality associated with influenza and respiratory syncytial virus in the United States. JAMA. 2003 Jan 8;289(2):179-86.

19. Voordouw AC, Sturkenboom MC, Dieleman JP, et al. Annual revaccination against influenza and mortality risk in community-dwelling elderly persons. JAMA. 2004 Nov 3;292(17):2089-95.

20. Centers for Disease Control and Prevention. Influenza and pneumococcal vaccination coverage among people aged $>$ or $=65$ years and people aged 18-64 years with diabetes or asthma-United States, 2003. MMWR Morb Mortal Wkly Rep. 2004 November 5;53(43):1007-12.

21. Zimmerman, RK. Lowering the age for routine influenza vaccination to 50 years: AAFP leads the nation in influenza vaccine policy. American Academy of Family Physicians. Am Fam Physician. 1999 Nov 1;60(7):2061-6, 2069-70.

22. United States Government Accountability Office (GAO). Flu vaccine: recent supply shortages underscore ongoing challenges. (GAO Rep. no. 05-177T.) Washington, DC: GAO, 2004.

23. United States Government Accountability Office (GAO). Influenza pandemic: challenges remain in preparedness. (GAO Rep. no. 05-760T.) Washington, DC: GAO, 2005.

24. United States Government Accountability Office (GAO). Flu vaccine: supply problems heighten need to ensure access for high-risk people. (GAO Rep. no. 01-624.) Washington, DC: GAO, 2001.

25. MacDonald R, Baken L, Nelson A, et al. Validation of self-report of influenza and 
pneumococcal vaccination status in elderly outpatients. Am J Prev Med. 1999 Oct; 17(3):249.

26. Nichol KL, Korn JE, Baum P. Estimation of outpatient risk characteristics and influenza vaccination status: validation of a self-administered questionnaire. Am J Prev Med. 1991 Jul-Aug;7(4):199-203.

27. Zimmerman RK, Raymund M, Janosky JE, et al. Sensitivity and specificity of patient self-report of influenza and pneumococcal polysaccharide vaccinations among elderly outpatients in diverse patient care strata. Vaccine. 2003 Mar 28;21(13-14):1486-91.

28. Diaz T, Des Jarlais, Vlahov D, et al. Factors associated with prevalent hepatitis C: differences among young adult injection drug users in lower and upper Manhattan, New York City. Am J Public Health. 2001 Jan;91(1):23-30.

29. Hurwitz ES, Haber M, Chang A, et al. Effectiveness of influenza vaccination of day care children in reducing influenza-related morbidity among household contacts. JAMA. 2000 Oct 4;284(13):1677-82.

30. Reichert TA, Sugaya N, Fedson DS, et al. The Japanese experience with vaccinating schoolchildren against influenza. N Engl J Med. 2001 Mar 22;344(12):889-96.

31. Longini IM Jr, Halloran ME. Strategy for distribution of influenza vaccine to highrisk groups and children. Am J Epidemiol. 2005 Feb 15;161(4):303-6.

32. Weycker D, Edelsberg J, Halloran ME, et al. Population-wide benefits of routine vaccination of children against influenza. Vaccine. 2005 Jan 26;23(10):1284-93.

33. Albert MR, Ostheimer KG, Breman JG. The last smallpox epidemic in Boston and the vaccination controversy, 1901-1903. N Engl J Med. 2001 Feb 1;344(5):375-9. 